\title{
La perspectiva cualitativa en los estudios sobre pobreza $^{1}$
}

\author{
Miguel A. Mateo Pérez \\ Departamento Sociología II \\ Universidad de Alicante \\ ma.mateo@ua.es
}

\section{INTRODUCCIÓN}

La perspectiva más empleada en los estudios internacionales sobre pobreza es la cuantitativa. Basada en el principio de que la realidad social se puede medir, cuantificar, esta propuesta reduce a datos numéricos cuestiones que son de índole más compleja. La encuesta es la técnica de recogida de información con más éxito en la investigación sobre pobreza y, en muchos casos, es la única empleada. Sin embargo, la utilización de técnicas cualitativas en el estudio sobre pobreza se observan en estudios que trabajan los procesos y causas de las situaciones de pobreza mientras que las más cuantitativas ponen su atención en las características numéricas de las situaciones de empobrecimiento.

Para estudiar la pobreza es necesaria una pluralidad epistemológica en las ciencias sociales, y en particular para la Sociología. Ya algunos autores han señalado que la barrera entre los llamados métodos cualitativos y cuantitativos (así como su enfrentamiento) es bastante frágil, o al menos discutible ${ }^{2}$. Hay ejemplos recientes en los que se ponen de manifiesto que los métodos cualitativos y cuan-

1 Este trabajo ha sido posible gracias a la financiación del Ministerio de Trabajo y Asuntos Sociales a través del Instituto de la Mujer, al proyecto dirigido por José María Tortosa «Indicadores dinámicos para el estudio del empobrecimiento de las mujeres (REF: IM-0003)». Agradezco a Clemente Penalva sus comentarios tan valiosos como amables.

2 Ver los trabajos en esa dirección de Luis Enrique Alonso: Alonso (1988) y Alonso (1998, cap. 1). También son importantes las aportaciones en la dirección de un tratamiento conjunto de ambas metodologías entendidas como epistemología. Lo anterior lo podemos encontrar en los trabajos de Sarabia y Zarco (1998) y Harrison (1994). 
titativos son complementarios y que las divisiones muchas veces responden a cuestiones meramente formalistas.

Desde nuestro punto de vista, la discusión entre un tipo de metodología u otra es estéril en la investigación sobre pobreza. Sabemos que en función de los objetivos y de la naturaleza de la información que queramos recoger, se habrá de plantear un tipo $\mathrm{u}$ otro de estrategia ${ }^{3} \mathrm{y}$ en muchos casos, necesitaremos acudir a triangulaciones metodológicas ${ }^{4}$.

En este trabajo planteamos varias cuestiones. En primer lugar, reivindicamos el papel en la investigación sobre pobreza de la metodología cualitativa y de las técnicas de recolección de información de este corte. Ello lo exponemos en el punto siguiente. En segundo lugar, exponemos el diseño metodológico cualitativo que hemos aplicado en la investigación «Indicadores dinámicos para el estudio del empobrecimiento de las mujeres en España», proyecto financiado por el Ministerio de Trabajo y Asuntos Sociales, Instituto de la Mujer. De este diseño se derivan los resultados en clave de proceso de empobrecimiento de las mujeres que se señalan en el cuarto y último punto, previo a la discusión.

\section{MARCO DE PARTIDA: MÉTODOS Y TÉCNICAS CUALITATIVAS EN EL ESTUDIO DE LA POBREZA}

La investigación cualitativa en los estudios sobre pobreza no es nueva. La utilización de técnicas de recogida de información desde la perspectiva cualitativa hicieron fortuna primeramente en estudios antropológicos biográficos ${ }^{5}$ y más tarde en estudios que mezclaban los elementos antropológicos con los sociológi$\cos ^{6}$. Desde la utilización de los «estudio de caso» mediante los llamados Métodos Intensivos Antropológicos y Sociológicos (técnicas etnográficos y observación participante) hasta los de Muestras Intencionales (Métodos Rápidos de Valoración, con técnicas como las entrevistas semi estructuradas, informantes clave o grupos de discusión focalizados), son ejemplos de la aplicación de la metodología cualitativa a los estudios sobre pobreza desde la década de los 70 .

Para estudiar la pobreza desde un punto de vista sociológico, no podemos descuidar la perspectiva cualitativa. Si desde la perspectiva cuantitativa buscamos los hechos, la medición, desde la cualitativa buscamos las cuestiones subjetivas. Esto tiene sentido si pensamos que la pobreza no es algo ajeno a las personas. Los varones y las mujeres perciben, explican y viven la pobreza de una forma personal y singular, aunque con ciertas regularidades que dan estructura a esas vivencias.

El siguiente paso es el diseño de instrumentos de recogida de información sensibles a este tipo de información cualitativa. El abanico de técnicas de reco-

${ }^{3}$ Estudios genéricos que tratan esta cuestión, ver: Alvira (1983); CONDE (1994); ORTI (1994); y BRYMAN (1988).

4 Bericat (1998).

5 LEWIS (1961).

${ }^{6}$ Chambers (1994, 958-959). 
gida de información cualitativas aplicadas a la investigación sobre la pobreza es amplio. La observación participante, las técnicas biográficas, la etnografía, el estudio de documentación y las entrevistas en profundidad son las técnicas más habituales ${ }^{7}$.

En la actualidad se ha recuperado la entrevista en grupo ${ }^{8}$ para las investigaciones internacionales. Esta recuperación no tiene más importancia que el organismo que la lleva a cabo. Si el Banco Mundial (organismo nada sospecho de estar adscrito a la metodología cualitativa) reconoce que la información cualitativa es importante en los estudios sobre pobreza, podemos hacernos una idea de la verdadera dimensión de las investigaciones cualitativas.

Nos hemos decantado por la utilización de la entrevista en profundidad para recoger la información cualitativa que necesitamos ${ }^{9}$. La entrevista en profundidad es un tipo de conversación. Conversaciones se pueden mantener de muchas maneras y con personas muy diferentes y en las investigaciones sobre pobreza en España, hay una cierta tradición en su utilización ${ }^{10}$. La conversación informal es una forma de mantener una relación verbal con alguien, sin embargo, no puede se considerada como una entrevista en profundidad.

Alonso ha definido la entrevista en profundidad como procesos comunicativos de extracción de información por parte de un investigador. Esto implica «que la información ha sido experimentada y absorbida por el entrevistado y que será proporcionada con una orientación o interpretación que muchas veces resulta más interesante informativamente que la propia exposición cronológica más o menos factuales» ${ }^{11}$.

Desde el punto de vista cualitativo de la investigación social, la entrevista en profundidad ofrece una serie de ventajas (también inconvenientes) sobre otras técnicas, también utilizadas en nuestra investigación aunque de manera complementaria. Un análisis más concreto de las ventajas e inconvenientes de la entrevista en profundidad nos puede ayudar a entender por qué hemos elegido esta técnica concreta para nuestra investigación.

\section{Ventajas de la entrevista en profundidad}

- El estilo abierto de la entrevista en profundidad nos permite obtener una gran riqueza informativa en las palabras y en los enfoques de los entrevistados;

7 Kingsbury et al. (1995).

8 Narayan, Chambers, Shah, Petesch (2000). Especialmente interesante es la proposición cuantitativa para el análisis de la información recogida en las entrevistas dirigidas.

9 Hemos decidido utilizar el término «entrevista en profundidad» a pesar de las observaciones que realiza al respecto de esa denominación Miguel Beltrán en BeLTRÁN (2000, cap. VII).

10 Una investigación para España (y sus resultados) se puede ver en CASADO (1990, 273-281). Ésta hace referencia a las entrevistas que el autor tuvo con Emiliano, un sin techo en la década de los 80 y 90 .

11 Alonso (1994, 225-226). 
- Proporciona al investigador la oportunidad de clarificación y seguimiento de preguntas y respuestas, incluso por caminos no previstos con anterioridad a la entrevista, en un marco de interacción directo y personalizado;

- Genera, en la fase inicial de cualquier estudio, puntos de vista, enfoques e hipótesis que se traducen en un proyecto posterior, además de preparar otros instrumentos técnicos de recogida de información, tanto cualitativos como cuantitativos ${ }^{12}$.

- Durante el desarrollo de muchas investigaciones, la entrevista en profundidad puede convertirse en un contraste a otro tipo de datos obtenidos de forma cuantitativa, además de facilitar la compresión de éstos.

\section{Limitaciones de la entrevista en profundidad}

- Las entrevistas en profundidad requieren de una inversión importante de tiempo. Las historias de vida y la observación participante necesitan aún más tiempo para ser aplicadas;

- Al ser una técnica basada en la interacción comunicativa, la entrevista en profundidad presenta problemas de reactividad y de fiabilidad y valide $z^{13}$.

Por último y comparándola con el grupo de discusión, en la entrevista en profundidad no podemos producir información del grupo, en el que destacan los efectos de sinergia, por ejemplo. Tampoco es igual el tipo de estimulación, seguridad y espontaneidad en una técnica y en otra ${ }^{14}$.

Pasando a la investigación empírica que hemos realizado, las entrevistas en profundidad las hemos combinado con la observación (importante para determinar la situación por ejemplo de la vivienda o del entorno social) y con el estudio de documentos que nos facilitaron la interpretación de muchos procesos de empobrecimiento ligados al deterioro del barrio. También hemos trabajado con información secundaria de las entrevistadas, cosa que dotó de significado o hizo cambiar algunas cuestiones contenidas en la guía de entrevista. Lamentablemente no pudimos realizar esta práctica con todas las entrevistadas, pero en las que se pudo realizar mucha información obtenida fue matizada.

Nuestras entrevistas en profundidad fueron de carácter retrospectivo. Quizá lo ideal habría sido aplicar técnicas biográficas ${ }^{15}$, ya que buscábamos el relato de las trayectorias vitales de las mujeres entrevistadas. Pero el tiempo del que disponíamos para hacer las entrevistas impedía materialmente, realizar historias o relatos de vida. En un relato de vida, el entrevistado habla de su vida. Una historia de vida puede ser construida con el relato, informaciones cruzadas de otras personas vinculadas a quien queremos construirle la historia de vida, y docu-

12 Valles $(1997,196-198)$.

13 Millar Crute y Hargie (1992). Ver en especial el capítulo sobre la entrevista sociólogia en DENZIN, N.K. (1970).

14 Stewart y Shamdasani $(1990,19)$.

15 González Monteagudo (1996). Ver también las aportaciones de Atkinson (1998, cap. 1) y AtKinson (1999, 191-196). 
mentos que impliquen cuestiones biográficas ${ }^{16}$. Además, la utilización de las historias de vida en la investigación sociológica vinculada a los procesos de empobrecimiento tampoco es nueva ${ }^{17}$.

Los relatos de vida (técnica biográfica de relato único) ${ }^{18}$, pueden formarse a partir de entrevistas en profundidad a una misma persona. Esto puede llevar a la construcción de una historia de vida de relato único. Nuestras entrevistas en profundidad (que podríamos decir se asemejan relativamente a los relatos de vida) fueron grabadas en cinta magnetofónica para su posterior tratamiento y análisis.

\section{NOTAS METODOLÓGICAS}

Para facilitar la exposición de las cuestiones metodológicas de las entrevistas en profundidad realizadas, podemos distinguir tres puntos: (1) la creación de la guía de la entrevista; (2) la realización de las entrevistas (selección de las entrevistadas, realización material, registro); y (3) las estrategias seguidas para el análisis de la información obtenida. Empecemos por las consideraciones oportunas respecto a la guía de la entrevista.

\subsection{Guía de la entrevista}

La guía de entrevista que hemos construido, contempla de forma explícita los contenidos de las entrevistas, aunque en muchos casos se tuvieron que adaptar a la realidad singular de cada una de las entrevistadas por separado. Es especialmente importante, en términos de esta investigación, el diseño de la entrevista. Por eso, conviene que nos detengamos en los temas más generales para más tarde plantear las «líneas de indagación» ${ }^{19}$ para cada una de las áreas temáticas que contempla el protocolo. Decir, una vez más, que se plantea la entrevista en profundidad con un marcado carácter retrospectivo, intentando construir el relato de vida de la entrevistada.

Los temas (o áreas) que tratamos en las entrevistas en profundidad están organizados en cinco partes:

1. Orígenes familiares, en la que establecemos los orígenes temporales de los procesos de empobrecimiento, el tipo de hogar en el que la entrevistada crece, los cambios principales en la vida familiar y del entorno en el que habita o habito.

16 Ver estas cuestiones en Goodson (2001); Mercade (1986); Sarabia (1985); Cachón (1989); y Santamarina y Marinas (1994). Para cuestiones vinculadas a los relatos de vida, ver BertauX (1989).

17 Relacionadas con las migraciones ver CRIADO (1997). Cuestiones más generales entre pobreza e historias de vida, ver Bowes, DAR y Sim (1997).

18 Pujadas (1992).

19 WeIss $(1994,46-47)$. 
2. El empleo y los ingresos son el segundo bloque de preguntas, buscándose establecer el grado de inserción en el mercado laboral, las trayectorias de empleo y el grado de seguridad financiera.

3. El tercer bloque de preguntas hacen referencia a las estrategias vitales que desarrollan las mujeres en situación de precariedad social. También entran en este bloque temáticos descubrir las desigualdades de consumo en el interior del hogar.

4. Salud. Se pregunta por el estado de salud de la entrevistada y del rol de cuidadora.

5. Por último, se optó por incluir un bloque de cuestiones en las que indagáramos por la definición y percepción de la pobreza por parte de las entrevistadas. En este sentido se posibilita la comparación en algunos aspectos con los estudios recién finalizados del Banco Mundial sobre «Las voces de los pobres».

La guía definitiva de la entrevista presenta estos temas desglosados. Además, se incluyen distintos reforzamientos y relanzamientos de la entrevista en aquellas cuestiones que consideramos que la conversación podría atravesar por momentos críticos ${ }^{20}$.

\subsection{Selección de las entrevistadas}

\section{Criterios de selección}

En principio teníamos previsto realizar 50 entrevistas a mujeres en situación de precariedad social para toda España. El número total de entrevistas realizadas fue de 57, de las cuales dos no fueron grabadas en cinta magnetofónica por petición explícita de las entrevistadas.

Para la selección de las entrevistadas y dadas las dificultades para acceder a estos sectores de población que fluctúan en el umbral de la pobreza, recurrimos a la red de Cáritas España (vinculando a diferentes Cáritas Diocesanas y Parroquiales). Se establecieron las diferentes posibilidades de selección, concluyéndose que lo más acertado si se buscaba la heterogeneidad era obtener una representación (no estadística) lo más amplia posible de los diferentes problemas sociales en los que estaban inmersas las entrevistadas. Esta realidad es conocida por las trabajadoras sociales de Cáritas Parroquial (en especial, las que trabajan vinculadas al tema de mujer) y es en estas personas en las que apoyamos la selección de las entrevistadas, en función de unos parámetros de edades.

El trabajo con las Cáritas Parroquiales también aseguraba una dispersión geográfica necesaria para nuestro estudio. De esta manera, dividimos España en cinco grandes regiones, con características respecto a la pobreza también diferentes:

- Sur y Oeste de España (Andalucía y Extremadura).

- Centro (Madrid, Castilla-León y Castilla-La Mancha).

20 Vallés (1992). 
- Norte (I) (Galicia).

- Norte (II) (País Vasco, Navarra).

- Levante (Cataluña, Comunidad Valenciana).

Así se distribuyeron las 50 entrevistas a realizar entre estos puntos geográficos, siguiendo el criterio de máxima variación en los problemas sociales presentes en las mujeres entrevistadas y con una distribución en las edades que permitan tener mujeres jóvenes (de entre 18 y 29 años) pero también mujeres entre los 30 y los 60 y también de más de 60 años. Como resumen del planteamiento general y teórico de las entrevistas, puede valer el cuadro siguiente:

CUADRo 1

Criterios de selección y entrevistas programas

\begin{tabular}{lcccccc}
\hline Región & & Edades & & Ámbito & & N. ${ }^{\circ}$ mínimo de entrevistas \\
\hline & $\mathbf{1 8 / 2 9}$ & $\mathbf{3 0 / 6 0}$ & $\mathbf{+ 6 0}$ & Rural & Urbano & \\
\hline $\begin{array}{l}\text { Andalucía } \\
\text { Extremadura }\end{array}$ & $\mathrm{X}$ & $\mathrm{X}$ & $\mathrm{X}$ & $\mathrm{X}$ & $\mathrm{X}$ & 15 \\
$\begin{array}{l}\text { Madrid } \\
\text { Castilla León }\end{array}$ & $\mathrm{X}$ & $\mathrm{X}$ & $\mathrm{X}$ & & $\mathrm{X}$ & 10 \\
\hline Galicia & $\mathrm{X}$ & $\mathrm{X}$ & $\mathrm{X}$ & $\mathrm{X}$ & $\mathrm{X}$ & 5 \\
\hline $\begin{array}{l}\text { País Vasco } \\
\text { Navarra }\end{array}$ & $\mathrm{X}$ & $\mathrm{X}$ & $\mathrm{X}$ & & $\mathrm{X}$ & 10 \\
$\begin{array}{l}\text { Cataluña } \\
\text { Valencia }\end{array}$ & $\mathrm{X}$ & $\mathrm{X}$ & $\mathrm{X}$ & & $\mathrm{X}$ & 10 \\
\hline
\end{tabular}

De esta forma, no podemos hablar de muestreo probabilístico (con la posibilidad de realizar generalizaciones al conjunto de la población de mujeres a través inferencia estadística), si no de un tipo de muestro intencional y no probabilístico (con el que podemos realizar generalizaciones utilizando la inferencia lógica) ${ }^{21}$.

\section{Ficha de recogida de información}

Al margen de la grabación de las entrevistas (cuando la entrevistada no indicara lo contrario) decidimos utilizar una ficha en la cual se recogiera la información más relevante de la entrevista, evidentemente, de manera anónima y sin posibilidad de identificar a nuestras entrevistadas. La ficha contiene, a grandes rasgos, diferentes niveles y tipos de información:

- Información técnica de las entrevistas: número de entrevista, número de cinta y código de la entrevista. Cada entrevista tiene un código asignado

21 Hammersley y AtKinson (1995). 
de manera que sirve de identificador directo de ésta, al resumir muchas características sociodemográficas de las entrevistadas. Así, una entrevista con el siguiente código: M/26/C/GR/U/NA quiere decir que la entrevistada es Mujer (M), de 26 años, Casada (C), de Granada (GR), que vive en ámbito Urbano (U) y que es española (NA).

- Datos de localización: son datos que se refieren al lugar, fecha, hora, duración y entrevistador que realiza la entrevista.

- Datos contextuales: cómo se accede a la entrevistada y quien es el contacto. Descripción detallada del barrio donde se realiza la entrevista (a veces se hace explícita el tipo de vivienda donde habita la entrevistada aunque no sea el lugar donde se realiza la entrevista).

- Resumen de la entrevista: Se relatan los siguientes puntos: Percepción y definición de la pobreza, cómo creen que llegaron a la pobreza y qué factores externos son importantes para explicar su situación, qué hacen para salir de la pobreza o sobrevivir y, en último lugar, las manifestaciones de violencia (directa o estructural) a lo largo del proceso vital.

- Ideas claves: Al final de la ficha se procura resumir la entrevista a través de unas palabras clave o tópicos que mejor caractericen la conversación.

\subsection{Análisis de los datos}

Una vez recogida la información, grabada en cinta magnetofónica y transcrita, podemos plantear el análisis de los datos, que son de naturaleza textual. Ante la imposibilidad de grabar las entrevistas en profundidad en vídeo y así trabajar con el lenguaje no verbal, debemos plantear las diferentes estrategias de análisis de las transcripciones literales.

Siguiendo a Tesch ${ }^{22}$, podemos distinguir entre el análisis estructural y el análisis de interpretación. El primero sitúa al investigador en una postura en la cual se presupone la existencia de estructuras o reglas subyacentes en los datos textuales que se deben descubrir. El análisis estructural parte de la identificación de las partes que forman la estructura para buscar más tarde las relaciones. Si las relaciones que se buscan son relaciones de interacción, estaríamos hablando de análisis del discurso. En este tipo de análisis se entremezclan cuestiones derivadas de la lingüística, de la psicología social, de la antropología, de la teoría de la comunicación.

A diferencia del análisis estructural, los denominados como análisis de interpretación no presuponen la existencia de estructuras y relaciones que el investigador debe descubrir. Pretenden identificar y clasificar los elementos que van apareciendo en los datos cualitativos y explorar sus hipotéticas conexiones. Desde este enfoque, podemos describir e interpretar los datos y las informaciones $\mathrm{y} / \mathrm{o}$ construir teorías. El análisis cualitativo es un proceso circular ${ }^{23}$ en el que se combinan la descripción, las conexiones y la clasificación. Así, vamos a considerar esas tres cuestiones para plantear un análisis cualitativo lo más amplio posible.

\footnotetext{
22 Tesch (1990).

23 DeY (1993, 31 y ss.).
} 


\section{RESULTADOS DE LA INVESTIGACIÓN: LAS TRAYECTORIAS DEL EMPOBRECIMIENTO}

Las entrevistas se orientaron hacia una narración retrospectiva. Más allá de querer saber la situación actual (importante para poder comprobar el nivel de empobrecimiento), nos interesaba tener información sobre los procesos. Diversas trabajos han señalado que los procesos de empobrecimiento son complejos ${ }^{24}$. Están vinculados con los orígenes sociales, el seno familiar en el que se nace, las oportunidades vitales que empiezan por la escolarización y por el éxito relativo dentro del sistema educativo, pasando por la formación de la pareja, hasta la situación actual. Una mujer de 60 años, ha vivido lo suficiente como para poder alejarse un instante y relatar con cierta perspectiva lo que le ha venido sucediendo en la vida. Pero también las jóvenes tiene que contar. El relato de las mujeres más jóvenes que hemos entrevistado nos permite, con todas las precauciones posibles, plantear escenarios futuros sobre el proceso de empobrecimiento de éstas. Muchas de las historias de las jóvenes son ya verdaderos pozos en los cuales encontrar la salida que ya no depende de las mujeres.

Si nos remontamos hasta el punto inicial en la historia de una persona, debemos indagar por sus orígenes. Sobre esta cuestión las entrevistas ofrecen una información valiosa sobre la situación de la familia en la cual nace y crece la entrevistada. Como en muchos casos es un tema espinoso, sobre todo cuando se han sufrido maltratos y abusos sexuales, la omisión de la información, las pocas referencias a una familia de origen, e incluso el recuerdo idílico de los padres son indicadores que tienen implícito un valor. Finalmente las entrevistadas suelen comentar cosas de su infancia y sus padres.

Estudiar de forma lineal la trayectoria vital de las mujeres entrevistadas es complicado. Hay cuestiones que sí son lineales, pero otras son claramente cíclicas. Sin embargo, son elementos presentes en todas las trayectorias estudiadas los que dan estructura a éstas.

Para realizar el análisis de trayectorias, en primer lugar planteamos un sistema de variables - proceso en la trayectoria vital de las mujeres entrevistadas y sus relaciones identificando lo que hemos denominado «momentos de crisis». Más tarde damos forma, con un eje temporal aproximado, a las combinaciones de variables - proceso vinculadas con el empobrecimiento. Por último, presentamos un esquema analítico general para estudiar las trayectorias vitales de las mujeres empobrecidas desde una perspectiva que integra variables, momentos de crisis y procesos de empobrecimiento.

\subsection{Variables - proceso en el estudio de las trayectorias vitales de las entrevistadas}

Como decíamos, la primera variable que influye en el proceso de empobrecimiento desde la perspectiva de la trayectoria vital, es el origen familiar.

24 Mateo (2001). 
«Mi padre hace muchos años que murió. Tenía un brazo así en seco, era inválido... y trabajaba de lo que podía. Y mi madre, pues, haciendo limpieza en las casas. $Y$, antiguamente, no era precisamente por el dinero... A veces era por... porque te daban la comida, o... te daban alguna cosita de dinero y... bueno, yo desde pequeñita pues... lo he pasado muy mal. Después ya... un poco de mayor, pues he tenido... baches... he tenido baches altos, baches bajos... he vivido a veces muy bien y otras veces he vivido muy mal...» (E-52)

Orígenes familiares ya relacionados con situaciones de pobreza o escasez, maltratos o privaciones de otro tipo, incrementan las posibilidades de vivir una vida pobre, desintegrada. Así, un origen familiar pobre condiciona toda una vida posterior. Porque, evidentemente, si no hay para comer, o dentro de la estructura del hogar, no se destinan los recursos suficientes para la educación por ejemplo, es fácil comprender que los procesos de empobrecimiento se inicien en el seno de la familia de la infancia. No debemos caer en el determinismo familiar, pero las mujeres (las niñas entonces) de hogares pobres tienen mucho más difícil abandonar las dinámicas del empobrecimiento. Muchas veces la salida o abandono de la casa de los padres, supone una mejora temporal de la situación. Sin embargo, en pocos años o meses, la situación se empeora, precisamente porque en la salida del hogar paterno se produce una ruptura en las relaciones familiares. Si esto es así, se pierde el elemento de solidaridad familiar que podría servir de apoyo a las mujeres en los momentos difíciles. Esto no tiene porqué suceder siempre. Pero siempre que sucede acelera el empobrecimiento de las mujeres.

«Es que si yo... si mi madre hubiera sido como es yo no estoy en su casa. Y ya me dijo a mi cuando yo tuve a mis hijos....igual que cuando me casé, que no volviera, que te vas porque tú quieres, aquí nadie te va a echar. Tú te arriesgas a lo que vas a tener. Entonces más claro no me lo pudo decir, igual que cuando tuve mis hijos. Tus hijos son tuyos, los cuidas tú, a mí no me digas para una fiesta que yo te los vaya a cuidar.... Los cuidaré el día que estés enferma, pero mientras tanto no.» (E-22)

Otra variable - proceso vinculada al empobrecimiento es la escolarización, o mejor dicho, el fracaso escolar. Que las mujeres no tuvieran éxito dentro del sistema educativo formal (las que entraron, aunque muchas otras ni siquiera pudieron acceder) es un lastre para combatir las situaciones de empobrecimiento. Es más, una preparación débil es un factor acelerador de los procesos de empobrecimiento. La falta de educación y preparación que permita a las mujeres desenvolverse en la sociedad es en sí pobreza. Y las mujeres son conscientes de ello, ya que a sus hijos intentan motivarlos para el estudio, aunque muchas veces las condiciones económicas no acompañen.

«Le digo: ya, pero..., pero es que tú tienes que estudiar. Ya que yo no he podio pues... tu tienes que estudiar. Porque yo... eso también me ha pasado a mí. Yo no me he podido sacar nada, no... he podido estar un año en el colegio y he estado nada más que hasta cuarto de E.G.B., porque me tenía que quedar con todos mis hermanos. Incluso yo lloraba porque no me dejaban ir al colegio» (E-05). 
Junto con la educación, una variable - proceso fundamental para entender el empobrecimiento es la inclusión/exclusión del mercado de trabajo. Aunque trabajen de manera remunerada, tienen cerrado el acceso a puestos de trabajo bien pagados y estables. Más que ningún otro actor económico, sus actividades laborales se insertan dentro del sector informal. Las que están limpiando tienen sesiones de trabajo desigualitariamente repartidas a lo largo de la semana o de los días. Además, hay una gran movilidad (entrada y salida) del mercado de trabajo y de actividades remuneradas vinculadas, precisamente al desempeño de una serie de roles provenientes de la socialización de instituciones que pueden ser potencialmente empobrecedoras.

Los roles a los que nos referimos son, básicamente tres: el rol de madre, el de pareja y el de cuidadora. A lo largo de la trayectoria vital, las mujeres desempeñan esos roles una o varias veces. Estos roles se han socializado y reforzado posteriormente gracias a instituciones como la familia. En la figura 1 se relacionan las variable - proceso, los roles e instituciones. No hay un diseño temporal en el esquema propuesto. Tómese como una primera descripción de las trayectorias vitales de las mujeres relacionadas con el empobrecimiento.

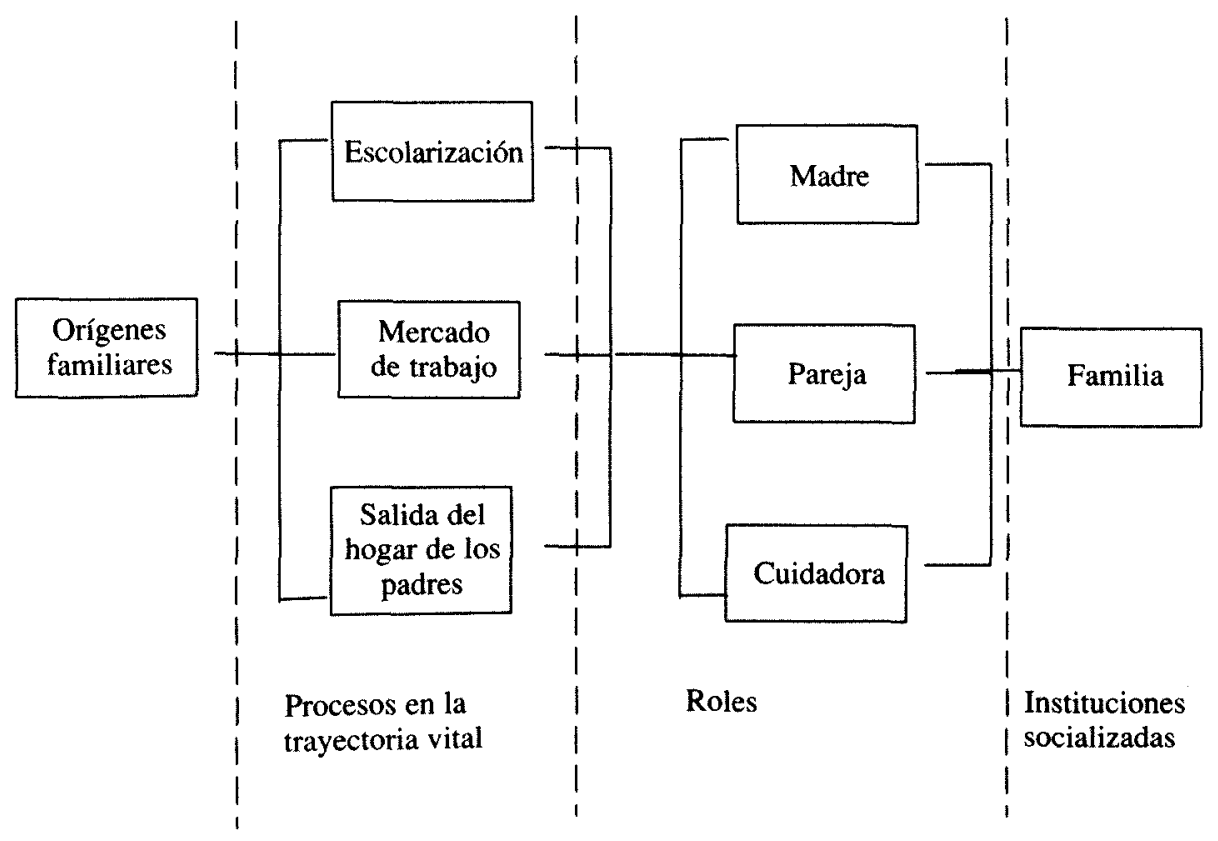

FIGURA 1. Procesos, roles e instituciones en la trayectoria vital de las mujeres pobres.

\subsection{Momentos de crisis e incremento de la pobreza}

En la trayectoria vital de las mujeres entrevistadas encontramos momentos de crisis en los que las situaciones de empobrecimiento se precipitan. Son los 
momentos en los que la vida de estas mujeres empeora e inician o marcan todo un proceso de empobrecimiento posterior.

Partiendo de la situación familiar de origen, que como hemos planteado previamente, condiciona las opciones futuras, hay cuatro momentos de crisis en las vidas de las entrevistadas: (1) La entrada y/o la salida del sistema educativo formal; (2) La entrada y/o la salida del mercado de trabajo; (3) El emparejamiento y el final de la vida en pareja; y (4) Tener hijos y/o desempeñar el rol de cuidadora (de niños o de adultos ancianos o personas con discapacidades).

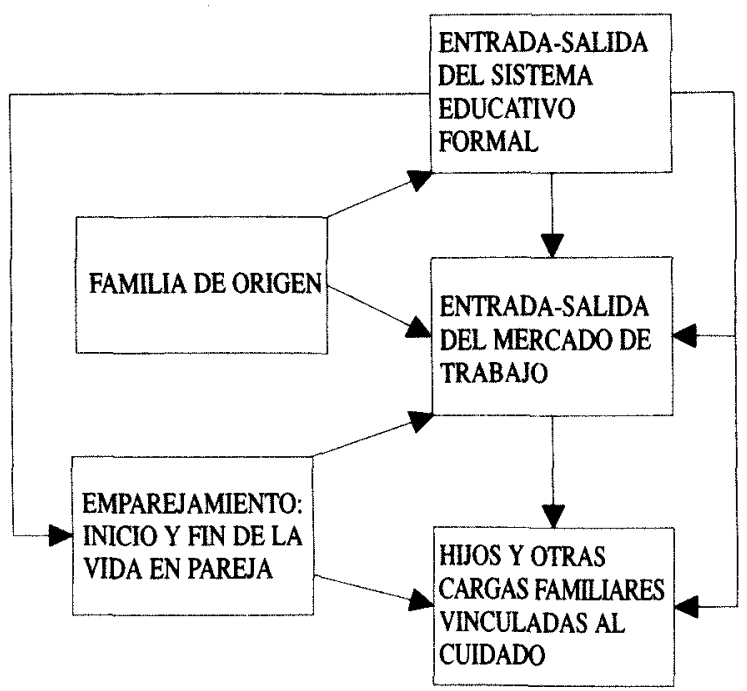

Figura 2. Momentos de crisis en los procesos de empobrecimiento.

¿En qué sentido afectan cada uno de los momentos de inflexión en la vida de las mujeres entrevistadas a los procesos de empobrecimiento?. La entrada y la salida del sistema educativo formal está condicionada, en principio, por la familia de origen, sus posibilidades económicas y la valoración que le merezca la formación de sus hijos/as. Las mujeres entrevistadas, excepto un caso aislado, no tienen un nivel educativo alto. Muchas no han tenido la oportunidad de ir a la escuela y las que lo han hecho, han tenido que abandonarla por diversos motivos. La salida del sistema educativo es uno de los procesos de empobrecimiento más claros a largo plazo. El déficit educativo va a ser un lastre que les va a impedir a estas mujeres insertase en el mercado de trabajo en ocupaciones relativamente bien pagadas.

Otro momento crítico que afecta a los procesos de empobrecimiento, es la entrada y la salida del mercado de trabajo. Aunque muchas de ellas trabajan, los trabajos que realizan las entrevistadas son mal pagados. Sin embargo, muchas veces son el único ingreso para el hogar y se convierte en imprescindible. Por eso es especialmente dramático cuando por diversos motivos, las mujeres que estaban trabajando dejan de trabajar. 
Es importante señalar que en la trayectoria vital de las entrevistadas, se producen entradas y salidas del mercado de trabajo casi de manera cíclica, relacionadas con otros factores o momentos de crisis. El emparejamiento, los hijos, las cargas familiares derivadas de su propia unidad doméstica o de la familia de origen y la baja o inexistente cualificación profesional y educativa, hacen que las mujeres entren y salgan en función de esos contextos del mercado de trabajo. Algunas no pueden ni siquiera iniciar una trayectoria laboral. Otras, al alcanzar una edad determinada o enfermar definitivamente, no vuelven a trabajar.

Hemos mencionado el emparejamiento como un momento de crisis en el empobrecimiento. La vida en pareja (independientemente del estado civil con el que se conviva) está muy relacionada con la pobreza de las mujeres. El emparejamiento supone la salida del hogar de los padres y muchas veces no se realiza en las mejores de las condiciones para la mujer.

Hay una asociación muy fuerte entre el primer hijo, la salida del hogar paterno y la pareja masculina. Al margen de los inicios complicados y que inician o continúan procesos de empobrecimiento, las mujeres señalan muy claramente que la «vida» que les han dado sus parejas no es la mejor de las posibles. Algunos no trabajan, otros gastan el dinero que ganan en el trabajo en sus asuntos, otros tienen cuentas pendientes con la justicia que están cumpliendo o tienen que cumplir. También debemos incluir dentro del emparejamiento los malos tratos físicos. La violencia doméstica está presente casi de manera permanente en la vida de las entrevistadas. Unas, algunas bofetadas. Otras, palizas continuadas en el tiempo. Las que denuncian se ven obligadas a salir de su domicilio con los hijos, hacia pisos de acogida fuera de las provincias de origen. El varón suele quedarse en la casa habitual. Algunas mujeres que han estado relacionadas con el ejercicio de la prostitución, señalan que las palizas son parte de la relación con su pareja. Lamentablemente los malos tratos se suelen silenciar en el interior de los hogares, en muchos casos por las situaciones de dependencia psicológica y material de las mujeres con respecto al varón.

La vida en pareja no tiene porqué ser con una sola persona. Muchos de los emparejamientos tempranos se rompen. Sin embargo, se van produciendo emparejamientos posteriores que parecen cortados por el mismo patrón que el anterior. En muy pocas ocasiones, la nueva pareja masculina supone un alivio en la pobreza. Todo lo contrario. Nuevos hijos, nuevas cargas familiares.

Sea como fuere, el emparejamiento o la disolución de éste implica siempre un incremento del empobrecimiento de las mujeres. Si se marcha, quedan libres de malos tratos, pero con los hijos a su cargo y sin haber trabajado nunca; si muere, puede dejar a las mujeres deudas y/o una pensión de viudedad que no le permite vivir con holgura. Sencillamente, las relaciones que se producen en el emparejamiento, afectan negativamente al bienestar de las mujeres.

Finalmente y a modo de resumen, podemos representar dentro de un eje dinámico, las trayectorias vitales de las mujeres entrevistadas relacionada con los procesos de empobrecimiento y los momentos críticos, así como otro tipo de información que nos permite vincular la trayectoria vital con la pobreza. Esto se representa en la figura 3. 


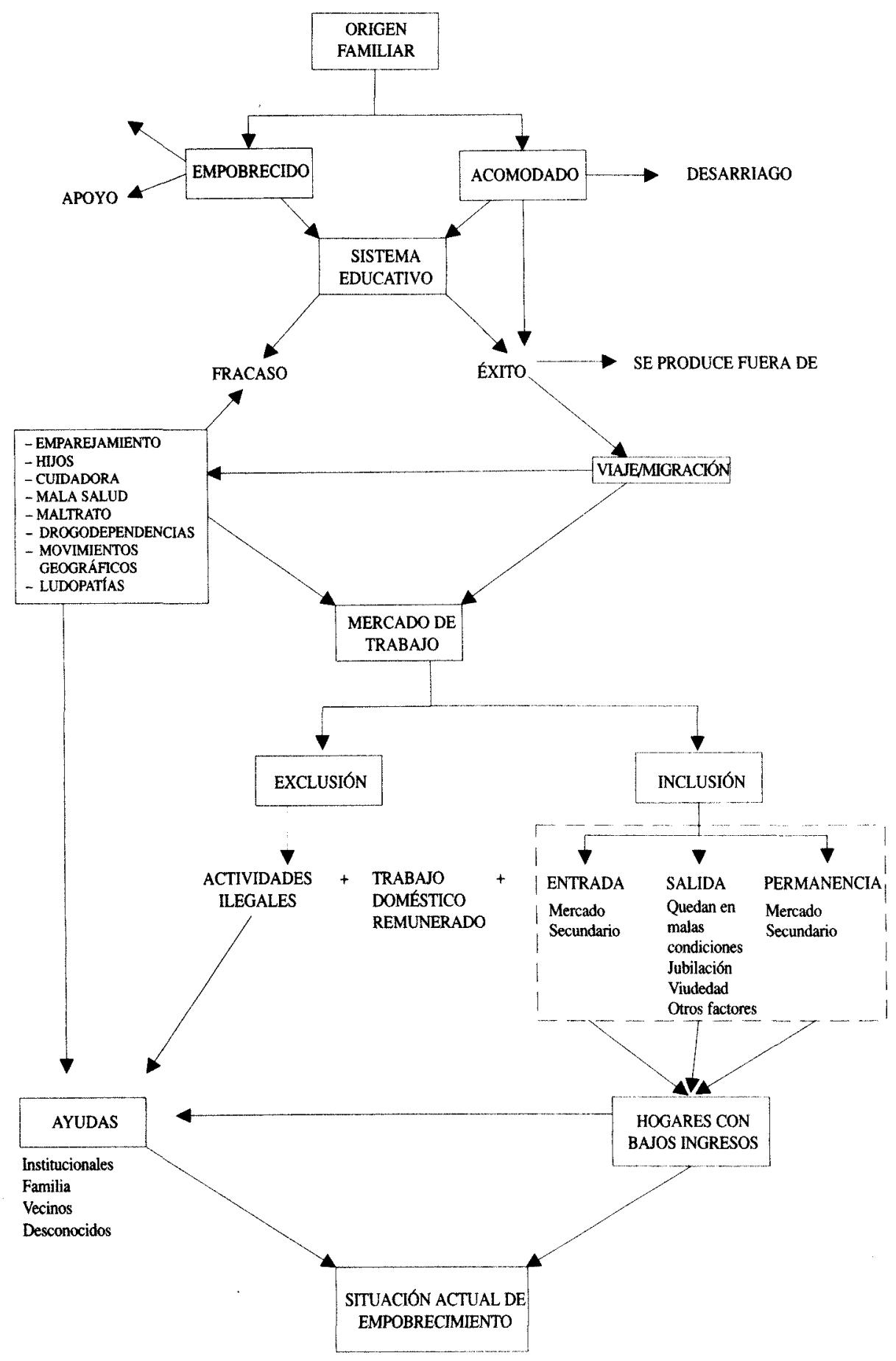

FiguRA 3. Trayectorias y procesos de empobrecimiento desde una perspectiva. 


\section{DISCUSIÓN. LA FUNESTA MANÍA DE CONTAR}

Según los estudios internacionales sobre pobreza para el 2001 realizados por UNIFEM, Banco Mundial o por el PNUD, se constata que la brecha entre varones y mujeres se acrecienta. Más mujeres pobres que varones. Más analfabetas, peor nutridas, con menos posibilidades vitales..., pero eso sí, con una esperanza media de vida al nacer mayor que la del varón. Este último dato, aunque anecdótico, sí señala algo que no se puede dejar de decir: que las mujeres vivan más no significa que la calidad de vida sea la deseada.

La funesta manía de contar pobres (varones y mujeres, pero especialmente mujeres) en estos últimos años en la investigación en España va acompañada de la funesta manía de no explicar. En términos académicos abogar por la cuantificación exclusivamente de la pobreza es algo que debería estar superado, pero que lamentablemente no lo está. Las/os economistas trabajan concienzudamente en la medición de la desigualdad y de la pobreza y reformulan con sofisticados análisis estadísticos las diferencias entre sexos respecto a la pobreza (habitualmente medida en términos de gasto y/o ingreso y en los hogares). Las/os sociólogas/os hemos acogido con entusiasmo las directrices más positivistas, pensando que así daríamos legitimidad (académica y científica, o lo que es peor, administrativa y política) a los estudios sobre pobreza.

Pero si hay alguna lección aprendida en los estudios cuantitativos sobre pobreza y género ${ }^{25}$ es que lo que se pretende elaborar estadísticamente no se corresponde con la realidad. La inclusión de la perspectiva cualitativa (entendiendo por perspectiva todo lo vinculado al proceso de investigación, desde el planteamiento de objetivos, metodología y técnicas de recolección de datos y análisis) en los estudios sobre pobreza desde la perspectiva de género no es algo exclusivamente complementario a los estudios cuantitativos. Es una necesidad desde cualquiera de los puntos de vista que se pretenda adoptar. Si se diseñan políticas sociales sin escuchar a las mujeres, se corre el riesgo de ayudar económicamente a las familias como unidad receptora, cuando se sabe empíricamente que la distribución de los bienes dentro del hogar no es igualitaria entre sus miembros ${ }^{26}$.

No se cuestionan, desde esta evidencia distinta vinculada a procesos más que a situaciones, las ayudas económicas y no económicas de las políticas sociales de lucha contra la pobreza. Simplemente se exige una adecuación a la realidad para conseguir que sean más efectivas. Para ello, la perspectiva cualitativa tiene mucho que decir, nunca mejor señalado.

\section{REFERENCIAS BIBLIOGRÁFICAS}

Alonso, L.E. (1988): «Entre el pragmatismo y el pansemiologismo. Notas sobre los usos (y abusos) del enfoque cualitativo en sociología», Revista Española de Investigaciones Sociológicas,.$^{\circ} 43$, pp. 157-168.

25 MATEO (2000).

26 Cantillón y Nolan (1996); ver especialmente el trabajo de Fritzell (1999). 
Alonso, L.E. (1994): «Sujeto y discurso: el lugar de la entrevista abierta en las prácticas de las Sociología cualitativa», en Delgado, J.M.; Gutierrez, J.: Métodos y técnicas cualitativas de investigación en Ciencias Sociales, Madrid: Síntesis, pp. 225-226.

Alonso, L.E. (1998): La mirada cualitativa en Sociología, Madrid.

AlviRA, F. (1983): «Perspectiva cualitativa - perpectiva cuantitativa en la metodología sociológica», Revista Española de Investigaciones Sociologicas, n. ${ }^{\circ} 22$, pp. 58-73.

Atkinson, P. (1999): «Voice and unvoice: review essay», Sociology, vol. 33, n. ${ }^{\circ}$, pp. 191-196.

AtKInSon, R. (1998): The life Story interview, Londres: Sage, capítulo 1.

Beltrán, M. (2000): Perspectivas sociales y conocimiento, Barcelona y México: Anthropos y UAM-Iztapalapa.

BERICAT, E. (1998): Integración de los métodos cuantitativo y cualitativo en la investigación social: significado y medida, Barcelona: Ariel.

Bertaux, D. (1989): «Los relatos de vida en el análisis social», Historia y fuente oral, 1 , pp. 87-96.

BowES, A.; DAR, N.; SIM, D. (1997): «Life histories in housing research: the case of pakistanis in Glasgow», Quality and Quantity, 31, 2, pp. 109-125.

BRYMAN, A. (1988): Quantity and Quality in Social Research, Londres: Unwin Hyman.

CACHÓN, L. (1989): ¿Movilidad social o trayectorias de clase?, Madrid: CIS-Siglo XXI.

Cantillon, S.; Nolan, B. (1996): «Are married women more deprived than their husbands?», Journal of Social Policy, 27, 2, pp. 151-171.

CASADO, D. (1990): Sobre la pobreza en España (1965-1990), Barcelona: Hacer.

CONDE, F. (1994): «Las perspectivas metodológicas cualitativa y cuantitativa en el contexto de la historia de las ciencias», en Delgado, J.M; Gutiérrez, J (coord.): Métodos y técnicas cualitativas de investigación en ciencias sociales, Madrid: Síntesis.

CRIADO, M.J. (1997): «Historias de vida: el valor del recuerdo, el poder de la palabra», Migraciones, 1, pp. 73-120.

DENZIN, N.K. (1970):The research act, Chicado: Aldine.

DEY, I. (1993): Qualitative data analysis. A user-friendly guide por Social Scientists, Londres: Routledge.

FRITZELL, J. (1999): «Incorporating gender inequality into income distribution research», International Journal of Social Welfare, 8, pp. 56-66.

GonZÁlez Monteagudo, J. (1996): «Las historias de vida. Aspectos históricos, teóricos y epistemológicos», Cuestiones pedagógicas, 12, pp. 223-242.

Goodson, I. (2001): «The story of life history: Origins of the life history method in Sociology», Identity, 0,2, pp. 129-142.

Hammersley, M. ; Atkinson, P. (1995): Ethnography. Principles in practice. Londres: Routledge.

HARRISON, W. (1994): «The inevitabilty of Integrated Methods», en SHERMAN, E. y ReID, W: Qualitative Research in Social Work, Nueva York: Columbia University Press.

KINGSBURY, D. et al. (1995): Alternative survey methodologies for monitoring and analyzing poverty in sub-saharan Africa, Washington: USAID.

Lewis, O. (1961): Antropología de la pobreza. Cinco familias, México: Fondo de Cultura Económico.

Chambers, R. (1994): «The origins and practice of participatory rural appraisal», World Development, 22, 7, pp. 958-959.

Mateo, M.A. (2000): «Pobreza infantil en veinticinco países industrialzados. Datos y evidencias desde el Luxembourg Income Study», Alternativas. Cuadernos de Trabajo Social, n. ${ }^{\circ} 8$, pp. 95-122. 
MATEO, M.A. (2001): «Desigualdad, pobreza y exclusión: conceptos, medidas y alternativas metodológicas», en TorTosA, J.M. (Coord.): Pobreza y perspectiva de género, Barcelona: Icaria.

MERCADE, F. (1986): «Metodología cualitativa e Historias de vida», Revista Internacional de Sociología, 3, 7/9, pp. 295-319.

Millar, R.; CRUTE, V.; Hargie, O. (1992): Professional interviewing, Londres: Routledge.

Narayan, D.; Chambers, R.; Shah, M.; Petesch, P. (2000): Voices of the Poor: Crying Out for Change. Nueva York: (Banco Mundial), Oxford University Press.

ORTf, A.(1994): «La confrontación de modelos y niveles epistemológicos en la génesis e historia de la investigación social», en Delgado, J.M; GutiérRez, J (coord.): Métodos y técnicas cualitativas de investigación en ciencias sociales, Madrid: Síntesis.

Pujadas, J.J. (1992): El método biografico: el uso de las historias de vida en Ciencias Sociales, Madrid: CIS.

Santamarina, C.; Marinas, J.C. (1994): «Historias de vida e historia oral», en Delgado, J.M; GUTIÉRREZ, J (coord.): Métodos y técnicas cualitativas de investigación en ciencias sociales, Madrid: Síntesis.

SARABIA, B., ZARCo, J. (1998): La metodología cualitativa en España, Madrid: CIS.

SARABIA, B. (1985): «Historias de vida», Revista Española de Investigaciones Sociologicas, 29, pp. 165-186.

Stewart, D.; Shamdasani, P. (1990): Focus groups. Theory and practice, Londres: Sage.

TESCH, R. (1990): Qualitative research: analysis types and software tools, Nueva York: The Falmer Press.

Vallés, M.S. (1992): «La entrevista psicosocial», en Clemente, M. (comp.): Psicología social. Métodos y técnicas de investigación. Madrid: Eudema, pp. 246-263.

VALLÉs, M.S. (1997): Técnicas cualitativas de investigación social. Reflexión metodológica y práctica profesional, Madrid: Síntesis.

WeIss, R. (1994): Learning from strangers. The art and method of qualitative interview studies, Nueva York: The free press. 